\title{
Analysis of Overseas Representatives Selection Using SMART And MCDM
}

\author{
Rizal Bagus Nur Achmad', Wildan Budiawan Zulfikar², Agung Wahana ${ }^{3}$ \\ \{rizalbagusnurachmad@student.uinsgd.ac.id ${ }^{1}$, wildan.b@uinsgd.ac.id², \\ wahana.agung@uinsgd.ac.id $\left.{ }^{3}\right\}$
}

Department of Informatics, UIN Sunan Gunung Djati Bandung, Indonesia ${ }^{1-3}$

\begin{abstract}
The government hopes for foreign representatives to be able to establish better international relations and advance each other in terms of economics, cultural education and the environment in the territory of a separate country. The problem that is happening right now is the presence of representatives not placed in accordance with the criteria and rules set by the foreign ministry. The purpose of this work is to conduct an analysis of prospective foreign representatives based on certain criteria using SMART and MCDM. The results of this study are recommendations for the ministry.
\end{abstract}

Keywords: MCDM, Overseas Representatives, SMART

\section{Introduction}

International Relations carried out on a basis to achieve certain goals, because of the objectives to be achieved, international relations are considered very important for a country. An international relationship is considered very beneficial for a country this is related to the benefits that can be obtained by establishing an international relationship. The many goals of countries that collaborate, expect the goals of the country to be achieved and the development of some of the country's achievements [1]-[3].

Diplomatic relations are relationships that are carried out between one country and another to meet each country's needs, this has been done since centuries ago. To be able to carry out diplomatic relations with other countries, it is necessary to first acknowledge that country, especially by the country that will receive a diplomatic representation of a country (Receiving State). Without recognition of the country, the opening of relations and diplomatic representation cannot be carried out [2], [3].

Each Representative will always be faced with the criteria needed according to the needs of the country. The country's needs can be seen from the Indexation of the Republic of Indonesia's Overseas Representatives as a result of the Foreign Minister's decision. The number of people placed in each embassy.

Based on previous research, SMART is used in cases that require a lot of attributes. In addition, SMART is a flexible decision-making method. MCDM is often used to rank alternatives given by evaluating criteria with alternatives [4]-[7]. It frequently used in case of selection, rank, etc and show a good result [8]-[10]. Both of these methods are suitable for use in this case. The proposed model is a system that can select several candidates. The intended election is the need of the embassy itself. The more election data, the more data that must be proposed. Thus the appropriate title is Analysis of this Model is proposed so that the system is 
specific, measurable, the targets set can still be achieved, relevant and have a clear time target work.

\section{Methodology}

The SMART method is used when carrying out data retrieval by the system, and at the same time when the process of finding data needed for the assessment of this method will work. MCDM method is used when calculating the data collection process that takes place in the calculation of each employee. In this work, SMART and MCDM will be synchronized from the initial data collection until the system produces candidates who will be sent abroad. SMART identifies the data needed by the system. MCDM assesses each employee according to the embassy of its employees. The combination of these two methods will help the system in collecting data, displaying data and storing data. MCDM will play a major role in producing the final value of the results of the election, and SMART helps retrieve data from the database.

\subsection{SMART}

This multi-attribute decision-making technique is based on the theory that each alternative consists of a number of criteria that have values and each criterion has a weight that illustrates how important it is compared to other criteria. This weighting is used to assess each alternative so that it gets the best alternative.

SMART is a flexible decision-making method. SMART is more widely used because of its simplicity in responding to the needs of decision-makers and how to analyze responses. The analysis involved is transparent so this method provides a high understanding of the problem and is acceptable to the decision-maker. The calculation steps performed in the SMART method are as follows:

1. Determine the Goal Weight Factor with a range of values between 1 and 10 .

2. Calculate the Normalized Weight Factor of each goal by comparing the weight value of each objective factor with the total number of goal factors (Total Goal Weight Factor).

3. Comparing the value of the same criteria for each alternative. Find the difference in value between the highest value and the lowest value. The difference results are divided by the number of score scales desired to determine the class intervals of each criterion.

4. After obtaining a range of classes for each criterion, we can determine the weight value for each alternative (intervals 1-10).

5. After process no. 4 , each weight is given a new predetermined value $(1=0 ; 2=0.25 ; 3=$ $0.5 ; 4=0.75 ; 5=1)$

6. Determine the percentage value of each alternative by multiplying the value obtained in the previous process by the Normalized Weight Factor value. Add up the value of the multiplication process and the total is multiplied by $100 \%$.

7. Displays alternative recommendations in order starting from the alternative with the highest percentage value to the lowest percentage value.

\section{$2.2 \mathrm{MCDM}$}

MCDM is a rather popular decision-making method used in many fields such as education and management sciences. Common components are found in most alternative MCDM 
algorithms, criteria, weights, and decision matrices. Alternatives are representations of choices given to users. For example, there are $m$ criteria $\left(C_{1}, \ldots, C_{m}\right)$ and alternative $n\left(A_{1}, \ldots, A_{n}\right)$. MCDM problems are usually represented in the form of decision tables as in figure 1 [4], [7], [11], [12].

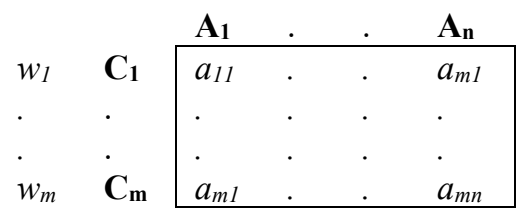

Figure 1. Decision Table

$a_{i j}$ values indicate alternative performance scores $\mathrm{A}_{\mathrm{j}}$ on $\mathrm{C}_{\mathrm{i}}$ criteria which is the preference of decision-makers. Each criterion has a weight that indicates the level of importance of the $\mathrm{C}_{\mathrm{i}}$ criteria in the decision-making process [11]-[14].

\section{Result and Discussion}

Based on the results of interviews with and the Law in the Ministry of Foreign Affairs regarding the selection of representatives, the available data is the data that will be selected in each data. Education is referred to in this ministerial decree as a reference in the placement of positions in the foreign ministry.

In an interview with the human resources department, it was explained that the language in the selection criteria did not play an important role in the selection, the most important thing for the election was the previous placements. If one of the employees has been placed at the A embassy, then the employee is not entitled to be placed at the A embassy for the second time. Then many placements determine whether the appraisal is feasible to be re-placed or not if the placement is 6 times the employee cannot be re-represented. Work units of employees are valued for their value of expertise. The results of observations and interviews are explained in detail in table 1 .

Table 1. Criteria for Representatives Selection

\begin{tabular}{lll}
\hline Attribute & Percentage & Status \\
\hline Position & $30 \%$ & Primary \\
Position Quantities & $15 \%$ & Primary \\
Skill & $10 \%$ & Optional \\
Last Position & $15 \%$ & Primary \\
Educational Background & $20 \%$ & Primary \\
Language & $10 \%$ & Optional \\
\hline
\end{tabular}

The assessment provided is the result of an interview with the Ministry of Foreign Affairs of the Republic of Indonesia. The following is an assessment table for each criterion. v1 = position, $\mathrm{v} 2=$ quantities, $\mathrm{v} 3=$ skill, $\mathrm{v} 4=$ last position, $\mathrm{v} 5=$ educational background, $\mathrm{v} 6=$ language. Table 2 explains the position attributes. ifl is very suitable data with the required criteria. if 2 is data that fits the required criteria. if 3 is enough data according to the required 
criteria. if4 is data that doesn't meet the required criteria. if5 is very data that doesn't fit the required criteria.

Table 2. Value of Position

\begin{tabular}{cccccc}
\hline Attribute & if1 & if2 & if4 & if5 & if6 \\
\hline v1 & 100 & 90 & 80 & 70 & 60 \\
\hline
\end{tabular}

Table 3 explains the attributes of quantities. In general, the number of representatives needed is according to the needs of the ministry. One position may require or accept 5 representatives and also 0 if the conditions do not require.

Table 2. Value of Position Quantities

\begin{tabular}{ccccccc}
\hline Attribute & 0 & 1 & 2 & 3 & 4 & 5 \\
\hline $\mathrm{v} 2$ & 100 & 90 & 80 & 70 & 60 & 50 \\
\hline
\end{tabular}

Table 3 explains the value of skills. if 1 is very suitable data with the required criteria. if 2 is data that fits the required criteria. if 3 is enough data according to the required criteria. if 4 is data that doesn't meet the required criteria. if 5 is very data that doesn't fit the required criteria.

Table 3. Value of Skill

\begin{tabular}{cccccc}
\hline Attribute & if1 & if2 & if4 & if5 & if6 \\
\hline v3 & 100 & 90 & 80 & 70 & 60 \\
\hline
\end{tabular}

Table 4 explains the value of the last position. ifplace $1=$ if it has never been placed there and ifplace $2=$ if it has never been placed there.

Table 4. Value of the Last Position

\begin{tabular}{ccc}
\hline Attribute & iftplace1 & ifplace2 \\
\hline $\mathrm{v} 4$ & 100 & 0 \\
\hline
\end{tabular}

Table 5 explains the value of the educational background. ifeb1 $=$ if you have completed Caraka Muda. ifeb2 = if you have completed Caraka Associate education. ifeb3 = if you have completed Caraka Utama education.

Table 5. Value of Educational Background

\begin{tabular}{ccccc}
\hline Attribute & ifpend1 & ifpend2 & ifpend3 & ifpend4 \\
\hline v5 & 60 & 70 & 80 & 90 \\
\hline
\end{tabular}

The value of language is explained in detail in table 6 . iflang $1=$ if the mastery of the language matches the required criteria. Iflang2 = if the mastery is not in accordance with the required criteria but has mastered the international language. Iflang $3=$ if the mastery is not in accordance with the required criteria but does not master the international language. 
Table 6. Value of Language

\begin{tabular}{cccc}
\hline Attribute & iflang1 & Iflang2 & Iflang3 \\
\hline $\mathrm{v} 6$ & 90 & 80 & 70 \\
\hline
\end{tabular}

The required part must have the greatest value in the assessment. The more placements that have been placed the fewer points the value gets. Judging expertise is seen from the work unit of each employee. The last placement determines a place that the employee in question cannot previously occupy. Education is determined from the latest education of the employee concerned.

Language assessment is determined by the placement to be placed. With a large weight value if the language occupied is mastered by the employee concerned. The final placement determines the assessment will be processed or not. If the employee concerned has been placed on a previous placement. Data that has been selected will not be re-valued.

Table 7. Result of the Model

\begin{tabular}{cccccccc}
\hline Candidate & va1 & va2 & va3 & va4 & va5 & va6 & va \\
\hline A & 27 & 9 & 6 & 15 & 18 & 8 & 83 \\
E & 21 & 15 & 6 & 15 & 14 & 8 & 79 \\
B & 24 & 9 & 6 & 15 & 16 & 8 & 78 \\
D & 27 & 13,5 & 6 & 0 & 18 & 9 & 73,5 \\
C & 21 & 12 & 6 & 0 & 16 & 8 & 63 \\
\hline
\end{tabular}

If a candidate has been placed in the embassy concerned, the employee is not entitled to elect prospective bank statements. Then, if the placement of someone has 6 or more times the placement of employees is not entitled to be placed in the existing embassy. The highest grade order for the position if the employee is a section head, the employee has the highest value in the position value. For bureau chiefs and subsections, the value decreases according to the last position level. For languages, in accordance with the city of the embassy placement for normal if you have an English base then already get a moderate value. For the highest score if it is the same as the city in the embassy and the lowest is an employee who does not master the international language or language at the embassy. For the value of expertise is determined by the value of the work unit of each candidate.

\section{Conclusion}

In this case, SMART and MCDM are effective and efficient in order to rank the representative representatives abroad. Both are very flexible in handling and adjusting the rules that apply to the system. Further works, we suggest adding more possible and critical criteria in order to improve effectiveness value of this proposed model. 


\section{References}

[1] D. W. Drezner, "Technological change and international relations," Int. Relations, vol. 33, no. 2, pp. 286-303, Jun. 2019.

[2] W. Bain and T. Nardin, "International relations and intellectual history," Int. Relations, vol. 31, no. 3, pp. 213-226, Sep. 2017.

[3] D. Voelsen and L. V. Schettler, "International political authority: On the meaning and scope of justified hierarchy in international relations,” Int. Relations, p. 004711781985639, Jul. 2019.

[4] Y. Song and M. Chen, "Fuzzy MCDM based on fuzzy relational degree analysis," J. Syst. Eng. Electron., vol. 13, no. 1, pp. 1-7, 2002.

[5] C.-T. Chang, W.-X. Zhao, and J. Hajiyev, "An Integrated Smartphone and Tariff Plan Selection for Taxi Service Operators: MCDM and RStudio Approach," IEEE Access, vol. 7, pp. 31457-31472, 2019.

[6] Y. Song and Y. Peng, "A MCDM-Based Evaluation Approach for Imbalanced Classification Methods in Financial Risk Prediction,” IEEE Access, vol. 7, pp. 84897-84906, 2019.

[7] M.-Y. Quan, Z.-L. Wang, H.-C. Liu, and H. Shi, "A Hybrid MCDM Approach for Large Group Green Supplier Selection With Uncertain Linguistic Information,” IEEE Access, vol. 6, pp. 50372 50383, 2018.

[8] M. Nassereddine and H. Eskandari, "An integrated MCDM approach to evaluate public transportation systems in Tehran," Transp. Res. Part A Policy Pract., vol. 106, pp. 427-439, Dec. 2017.

[9] Z. Hong et al., "An integrated approach for multi-objective optimisation and MCDM of energy internet under uncertainty,” Futur. Gener. Comput. Syst., vol. 97, pp. 90-104, Aug. 2019.

[10] W. Serrai, A. Abdelli, L. Mokdad, and Y. Hammal, "Towards an efficient and a more accurate web service selection using MCDM methods,” J. Comput. Sci., vol. 22, pp. 253-267, Sep. 2017.

[11] P. K. Ghosh, S. Chatterjee, and B. K. Saha Roy, "Optimal PMU placement solution: graph theory and MCDM-based approach," IET Gener. Transm. Distrib., vol. 11, no. 13, pp. 3371-3380, Sep. 2017.

[12] N. Liu, J. Zhang, H. Zhang, and W. Liu, "Security Assessment for Communication Networks of Power Control Systems Using Attack Graph and MCDM," IEEE Trans. Power Deliv., vol. 25, no. 3, pp. 1492-1500, Jul. 2010.

[13] K. Wang and F. Wei, "Robust data envelopment analysis based MCDM with the consideration of uncertain data," J. Syst. Eng. Electron., vol. 21, no. 6, pp. 981-989, Dec. 2010.

[14] T. L. Ramani, L. Quadrifoglio, and J. Zietsman, "Accounting for Nonlinearity in the MCDM Approach for a Transportation Planning Application," IEEE Trans. Eng. Manag., vol. 57, no. 4, pp. 702-710, Nov. 2010. 